\title{
A hybrid heuristic for inventory routing problem
}

\section{N. Ramkumar, P. Subramanian and T.T. Narendran*}

Department of Management Studies, Indian Institute of Technology Madras, Chennai-600036, Tamil Nadu, India E-mail: ramkumar.kpm@gmail.com E-mail: sathish.subramanian84@gmail.com

E-mail: ttn@iitm.ac.in

*Corresponding author

\section{K. Ganesh}

Global Business Services - Global Delivery, IBM India Private Limited,

Bandra East, Mumbai-400051, Maharashtra, India

E-mail: ganesh.ko@in.ibm.com

E-mail:koganesh@yahoo.com

\begin{abstract}
This paper addresses an inventory routing problem in vendor managed inventory systems with explicit consideration of buffer stock levels at warehouses. The problem involves a manufacturer delivering a product to a set of warehouses with available fleet capacity with the objective of minimising transportation and inventory costs. We have developed an integer linear programme (ILP) and proposed a hybrid heuristic for the problem. In the proposed heuristic, inventory is allocated using an ILP, vehicles are allotted to customers on the basis of proximity and routes for vehicles are determined using simulated annealing. The proposed heuristic is validated with different datasets and found to be performing well.
\end{abstract}

Keywords: inventory routing problem; IRP; integer linear programme; ILP; heuristic; simulated annealing; SA.

Reference to this paper should be made as follows: Ramkumar, N., Subramanian, P., Narendran, T.T. and Ganesh, K. (2011) 'A hybrid heuristic for inventory routing problem', Int. J. Electronic Transport, Vol. 1, No. 1, pp.45-63.

Biographical notes: N. Ramkumar is currently pursuing his Masters at the Department of Management Studies, Indian Institute of Technology Madras. $\mathrm{He}$ received his Bachelors in Industrial Engineering from College of Engineering Guindy, Anna University. His research interests include supply chain management and inventory routing. He has publications in international journals. 
P. Subramanian is a Research Scholar at the Department of Management Studies, Indian Institute of Technology Madras. He received his Bachelors in Industrial Engineering from College of Engineering, Guindy, Anna University and Indian Institute of Industrial Engineering, Navi Mumbai, India. His research interests include closed loop supply chain management and inventory routing. He has publications in international journals.

T.T. Narendran is a Professor of Operations Management at the Indian Institute of Technology Madras, India. He obtained his PhD and Masters in Industrial Engineering both from Indian Institute of Technology Madras, India. His research interests include supply chain management, logistics, vehicle routing and ergonomics. He has done extensive research in the areas of cellular manufacturing systems and flexible manufacturing systems and has published several papers in leading international journals. He is a reviewer for leading international journals.

K. Ganesh is a Senior Consultant at Global Business Services, Global Delivery, IBM India Private Limited, Mumbai, India. He holds a Doctorate from IIT Madras. His research interests lie in the application of heuristics, meta-heuristics and decision-making tools to logistics and supply chain management. He has published several papers in leading research journals such as the European Journal of Operational Research and International Journal of Advanced Manufacturing Technology.

\section{Introduction}

Enhancement of supply chain through integration of supply chain drivers is gaining momentum because of the tangible and intangible benefits over the entire supply chain. It has become indispensable to address supply chain decisions from an integrated point of view considering various drivers since addressing a single function (transportation) may lead to disruption of other supply chain functions (inventory, production and location). Over the years, the emergence of supply chain management (SCM) has shifted the responsibility for inventory control to the vendors, leading to the concept of vendor managed inventory (VMI), a distribution and inventory control system in which the stock positions and demand rates are known across the supply chain (Disney and Towill, 2002). It is a streamlined approach to inventory and order fulfilment in which a vendor continuously and automatically replenishes a trading partner's inventory. In order to meet customer demand, vendor must ensure appropriate quantities of storage at the point of demand and must ensure optimal distribution plans that include routing of the distribution vehicles. This requirement has evolved as the inventory routing problem (IRP), which focuses on the coordination of inventory replenishment and transportation. IRP involves distribution through chosen routes to a set of customers with varying daily demand and managing inventory, such that no customer runs out of the commodity at anytime, at minimum total cost. In this paper, we solve the issue of distribution of products to multiple warehouses from a manufacturing plant with the objective of minimising inventory and transportation costs. The aim is to develop a solution approach which is computationally efficient to handle large datasets and real life cases of IRP. 


\section{Literature review}

Federgruen and Zipkin (1984), Burns et al. (1985), Blumenfeld et al. (1985) and Roundy (1985) are among the earliest to study the IRP. Variants of the problem have evolved, based on characteristics such as:

1 nature of demand

2 network topology

3 routing

4 inventory

5 fleet composition

6 fleet size.

Over the last three decades, IRP has been studied in various contexts and several approaches to solution have been proposed. Since the problems are complex, much of the literature is on development of methodology under various assumptions. The majority of the studies have focused on IRPs involving tactical decisions and infinite horizon (Blumenfeld et al., 1985; Gallego and Simchi-Levi, 1990; Stacey et al., 2007; Raa and Aghezzaf, 2008, 2009). Strategic IRP has been studied by Larson (1988), and Webb and Larson (1995). Andersson et al. (2010) provided a comprehensive literature review on IRPs and emphasised the need for models that address real-world problems. In this paper, we study an IRP in a one-to-many network with deterministic demand at warehouses. A brief summary of literature has been presented in Table 1 .

Table 1 Summary of literature

\begin{tabular}{|c|c|c|c|c|}
\hline S. no. & Author and year & Problem & Objective & Solution methodology \\
\hline 1 & Chandra (1993) & IRP & $\begin{array}{l}\text { Warehouse } \\
\text { replenishment cost, } \\
\text { inventory holding } \\
\text { cost and } \\
\text { transportation cost }\end{array}$ & Heuristics \\
\hline 2 & $\begin{array}{l}\text { Bramel and } \\
\text { Simchi-Levi } \\
(1995)\end{array}$ & $\begin{array}{l}\text { Routing problems; } \\
\text { capacitated vehicle } \\
\text { routing problem and } \\
\text { IRP }\end{array}$ & $\begin{array}{l}\text { Inventory holding } \\
\text { cost, transportation } \\
\text { cost and fixed } \\
\text { ordering cost }\end{array}$ & $\begin{array}{l}\text { Location-based } \\
\text { heuristics }\end{array}$ \\
\hline 3 & $\begin{array}{l}\text { Bard et al., } \\
(1998)\end{array}$ & $\begin{array}{l}\text { IRP with satellite } \\
\text { facilities }\end{array}$ & $\begin{array}{l}\text { Annual operating } \\
\text { costs and distance }\end{array}$ & $\begin{array}{l}\text { Heuristics: randomised } \\
\text { Clarke-Wright, GRASP } \\
\text { and modified sweep }\end{array}$ \\
\hline 4 & $\begin{array}{l}\text { Kim and Kim } \\
(2000)\end{array}$ & IRP & $\begin{array}{l}\text { Inventory holding } \\
\text { cost and } \\
\text { transportation cost }\end{array}$ & Lagrangian relaxation \\
\hline 5 & $\begin{array}{l}\text { Bertazzi et al., } \\
(2002)\end{array}$ & $\begin{array}{l}\text { IRP with } \\
\text { deterministic order } \\
\text { up-to levels }\end{array}$ & $\begin{array}{l}\text { Inventory holding } \\
\text { cost and } \\
\text { transportation cost }\end{array}$ & Heuristics \\
\hline
\end{tabular}


Table 1 Summary of literature (continued)

\begin{tabular}{|c|c|c|c|c|}
\hline S. no. & Author and year & Problem & Objective & Solution methodology \\
\hline 6 & $\begin{array}{l}\text { Campbell and } \\
\text { Savelsberg } \\
(2004)\end{array}$ & $\begin{array}{l}\text { IRP with time } \\
\text { windows }\end{array}$ & Transportation cost & $\begin{array}{l}\text { Decomposition with } \\
\text { integer programming } \\
\text { and routing and } \\
\text { scheduling heuristics }\end{array}$ \\
\hline 7 & $\begin{array}{l}\text { Rusdiansyah and } \\
\text { Tsao (2005) }\end{array}$ & $\begin{array}{l}\text { Integrated inventory } \\
\text { and periodic vehicle } \\
\text { routing problem with } \\
\text { time-windows } \\
\text { (IPVRPTW) }\end{array}$ & $\begin{array}{l}\text { Average inventory } \\
\text { holding cost and } \\
\text { transportation cost }\end{array}$ & $\begin{array}{l}\text { Mathematical } \\
\text { formulation, heuristics }\end{array}$ \\
\hline 8 & $\begin{array}{l}\text { Aghezzaf et al. } \\
(2006)\end{array}$ & $\begin{array}{l}\text { IRP with } \\
\text { multi-tours }\end{array}$ & $\begin{array}{l}\text { Inventory holding } \\
\text { cost and } \\
\text { transportation cost }\end{array}$ & $\begin{array}{l}\text { Approximation method } \\
\text { based on column } \\
\text { generation; an efficient } \\
\text { savings-based method } \\
\text { to generate the columns } \\
\text { (multi-tours). }\end{array}$ \\
\hline 9 & $\begin{array}{l}\text { Abdelmaguid } \\
\text { and Dessouky } \\
(2006)\end{array}$ & $\begin{array}{l}\text { IRP with } \\
\text { backlogging (IRPB) }\end{array}$ & $\begin{array}{l}\text { Transportation, } \\
\text { inventory and } \\
\text { backlogging costs. }\end{array}$ & $\begin{array}{l}\text { Heuristics and genetic } \\
\text { algorithm }\end{array}$ \\
\hline 10 & $\begin{array}{l}\text { Archetti et al., } \\
\text { (2007) }\end{array}$ & $\begin{array}{l}\text { IRP with } \\
\text { deterministic order } \\
\text { up-to levels }\end{array}$ & $\begin{array}{l}\text { Inventory holding } \\
\text { cost and } \\
\text { transportation costs }\end{array}$ & $\begin{array}{l}\text { Branch and cut } \\
\text { algorithm }\end{array}$ \\
\hline 11 & $\begin{array}{l}\text { Al-Khayyal and } \\
\text { Hwang (2007) }\end{array}$ & $\begin{array}{l}\text { Maritime routing and } \\
\text { scheduling for multi- } \\
\text { commodity liquid } \\
\text { bulk }\end{array}$ & $\begin{array}{l}\text { Travel costs, loading } \\
\text { and unloading costs }\end{array}$ & $\begin{array}{l}\text { Mixed integer linear } \\
\text { programme }\end{array}$ \\
\hline 12 & $\begin{array}{l}\text { Yugang et al. } \\
(2008)\end{array}$ & $\begin{array}{l}\text { IRP with split } \\
\text { delivery }\end{array}$ & $\begin{array}{l}\text { Inventory holding } \\
\text { costs and } \\
\text { Transportation costs }\end{array}$ & $\begin{array}{l}\text { Lagrangian relaxation } \\
\text { followed by a } \\
\text { decomposition } \\
\text { algorithm }\end{array}$ \\
\hline 13 & $\begin{array}{l}\text { Abdelmaguid } \\
\text { et al. (2009) }\end{array}$ & $\begin{array}{l}\text { IRP with } \\
\text { backlogging (IRPB) }\end{array}$ & $\begin{array}{l}\text { Balancing } \\
\text { transportation, } \\
\text { Inventory and } \\
\text { Backlogging costs. }\end{array}$ & $\begin{array}{l}\text { Constructive and } \\
\text { improvement heuristics }\end{array}$ \\
\hline 14 & $\begin{array}{l}\text { Taarit et al. } \\
(2009)\end{array}$ & IRP & $\begin{array}{l}\text { Fixed and variable } \\
\text { transportation costs }\end{array}$ & Lagrangian heuristics \\
\hline 15 & $\begin{array}{l}\text { Oppen et al. } \\
(2010)\end{array}$ & $\begin{array}{l}\text { IRP - livestock } \\
\text { collection }\end{array}$ & Travel distance & $\begin{array}{l}\text { Exact method based on } \\
\text { column generation }\end{array}$ \\
\hline
\end{tabular}

We develop an integer linear programme (ILP) for the problem. A hybrid heuristic is introduced to solve the problem and is compared with upper bound solutions obtained by solving the ILP using ILOG CPLEX 9.0.

The remainder of the paper is organised as follows. In Section 3, problem description is detailed. Section 4, presents the assumptions made in this study and discusses the mathematical model for the IRP. This is followed by description of the proposed heuristic in Section 5. The results are discussed in Section 6. Section 7 presents the conclusions. 


\section{Problem descriptions}

We consider a VMI system in a network with a manufacturing facility and W warehouses. Warehouses face deterministic time varying demand over a finite time horizon $T$. To deal with uncertainties, a safety stock is maintained at warehouses. Manufacturing facility supply finished products to warehouses under VMI contract. Vehicles are routed from manufacturing plant to $W$ warehouses, each with capacity VCAP.

A vehicle with a route $r$ in a time period $t$ starts with pick-up node (manufacturing plant) to collect the shipment quantities and sequentially visits the delivery nodes (warehouses) to deliver the shipment. In any route $r \in R$, a set of feasible routes, the visit of a delivery node by multiple vehicles is not allowed.

For a multi-product environment with products having negligible variances in their inventory holding costs and storage space, the demands of the products can be consolidated as for a single item or bundle or package (Abdelmaguid et al., 2009). Now, the task is to analyse a combined inventory and routing problem and determine an optimal inventory and distribution plan.

\section{Solution methodology}

This section consists of a mathematical model (ILP) and a hybrid heuristic for the problem under study.

The major assumptions for the proposed model are stated below

1 finished goods inventory exists only in the warehouse

2 transportation cost between manufacturer and warehouse is based on distance

3 each vehicle can tour only once in a time period

4 vehicles are homogeneous

5 all vehicles start and end at same node (virtual origin)

6 shortages and back-ordering are not allowed.

\subsection{Mathematical model}

The objective function of the ILP has the following cost components:

1 inventory carrying cost at warehouse

2 transportation cost between nodes, based on distance, for manufacturers and warehouses

3 fixed vehicle-operating cost. 


\subsubsection{Notations}

\begin{tabular}{lll}
\hline$V$ & Set of homogenous vehicles & \\
$W$ & Set of warehouses & \\
$T$ & Time horizon & \\
$\xi$ & Set of feasible arcs between manufacturer and & \\
& warehouses for the chosen network & \\
$d_{u}$ & Demand at warehouse i in time period $t$ & $\forall i \in W, \forall t \in T$ \\
$C_{i j}$ & Cost of transportation between node $i$ and $j^{1}$ & $\forall i, j \in \xi$ \\
$F C$ & Fixed operating cost for using a vehicle & \\
$S S_{i}$ & S level at warehouse $i$ & $\forall i \in W$ \\
$I C_{i}$ & Inventory carrying cost /unit/unit time in & $\forall i \in W$ \\
& warehouse i & \\
\hline
\end{tabular}

\subsubsection{Decision variables}

\begin{tabular}{lll}
\hline$I_{i}^{t}$ & Inventory at warehouse $i$ in time period $t$ & $\forall i \in W, \forall t \in T$ \\
$Q_{i, v}^{t}$ & Quantity delivered in node $i$ by vehicle $v$ in time period $t$ & $\forall i \in W, \forall v \in V$, \\
$X_{i, j, v}^{t}- \begin{cases}1-\text { if vehicle } v \text { drives from node } i \text { to } j \text { in time period } t & \forall t \in T \in \xi, \forall v \in V, \\
0-\text { Otherwise } & \forall t \in T\end{cases}$ \\
\hline
\end{tabular}

Minimise

$$
\sum_{t \in T} \sum_{i \in W} I C_{i} \cdot I_{i}^{t}+\sum_{t \in T} \sum_{j \in \xi} \sum_{v \in V} C_{i, j} \cdot X_{i, j, v}^{t}+\sum_{t \in T} \sum_{j \in W} \sum_{v \in V} F C \cdot X_{0, j, v}^{t}
$$

Subject to

- Constraint set (2) ensures flow of each vehicle $v$ through each node $h$ in a time period $t$.

$$
\sum_{i \in\{0, W\}} X_{i, h, v}^{t}-\sum_{j \in\{W, N\}} X_{h, j, v}^{t}=0 \quad \forall i \in W, \forall v \in V, \forall t \in T
$$

- Constraint set (3) limits each delivery node to be visited by only one vehicle.

$$
\sum_{v \in V} \sum_{h \in\{W, N\}} X_{i, h, v}^{t} \leq 1 \quad \forall i \in W, \forall t \in T
$$

- Constraint set (4) enforces vehicle $v$ not to visit node $i$, if there is no load to be delivered at that node.

$$
Q_{t, v}^{t}-V C A P . \sum_{h \in\{W, N\}} X_{i, h, v}^{t} \leq 0 \quad \forall i \in W, \forall v \in V, \forall t \in T
$$


- Constraint set (5) restricts the total quantity picked up by a vehicle $v$ in time period $t$ to be within vehicle capacity.

$$
\sum_{i \in W} Q_{i, v}^{t}-V C A P \cdot \sum_{i \in W} X_{0, i, v}^{t} \leq 0 \quad \forall v \in V, \forall t \in T
$$

- Constraint set (6) conserves the flow of material at delivery node $i$ during time $t$

$$
\sum_{v \in V} Q_{i, v}^{t}+I_{i}^{t-1}-I_{i}^{t}=d_{i t} \quad \forall i \in W, \forall t \in T
$$

- Inventory in warehouses at any time $t$ should be maintained above pre-specified safety stock level.

$$
I_{i}^{t} \geq S S_{i} \quad \forall i \in W, \forall t \in T
$$

- Constraint sets (8), (9) and (10) deal with elimination of sub-tours.

$$
\begin{array}{ll}
S_{0, v}^{t}=0 & \\
S_{0, v}^{t}+\left(S_{\max }+C_{0, j}\right) \cdot X_{0, j, v}^{t}-S_{j, v}^{t} \leq S_{\max } & \forall j \in W, \forall v \in V, \forall t \in T \\
S_{i, v}^{t}+\left(S_{\max }+C_{i, j}\right) \cdot X_{i, j, v}^{t}-S_{j, v}^{t} \leq S_{\max } & \forall i \in W, \forall j \in\{W, N\}, i \neq j, \\
\forall v \in V, \forall t \in T & \\
\text { integral variables : } I_{i}^{t}, Q_{i, v}^{t}, S S_{i} & \text { binary variables : } X_{i, j, v}^{t} \in\{0,1\}
\end{array}
$$

\section{Hybrid heuristic}

IRPs are computationally hard to solve as it comprises of vehicle routing problem (VRP), a well-known NP-hard problem to be solved for multiple time periods (Abdelmaguid et al., 2009). To tackle this issue of computational difficulty, a blend of techniques has been used and a hybrid heuristic has been proposed for solving the problem. The proposed heuristic has three stages viz., inventory allocation, clustering of warehouses and routing of vehicles. The three stage framework adopted in this study is shown in Figure 1. Inventory allocation to $W$ warehouses for $T$ periods is carried out by an ILP which considers vehicle capacity and safety stock constraints, clustering of delivery nodes (warehouses) with replenishment is performed using K-means clustering for each time period and the corresponding routing sequences for vehicles are determined using simulated annealing (SA).

\subsection{Inventory allocation - ILP}

An ILP is developed to determine the allocation quantity, $Q_{w t}^{\prime}$ for $W$ warehouses in $T$ time periods and the number of vehicles used in each time period, $n_{t}$. The model is as follows. 
Figure 1 Framework for the hybrid heuristic

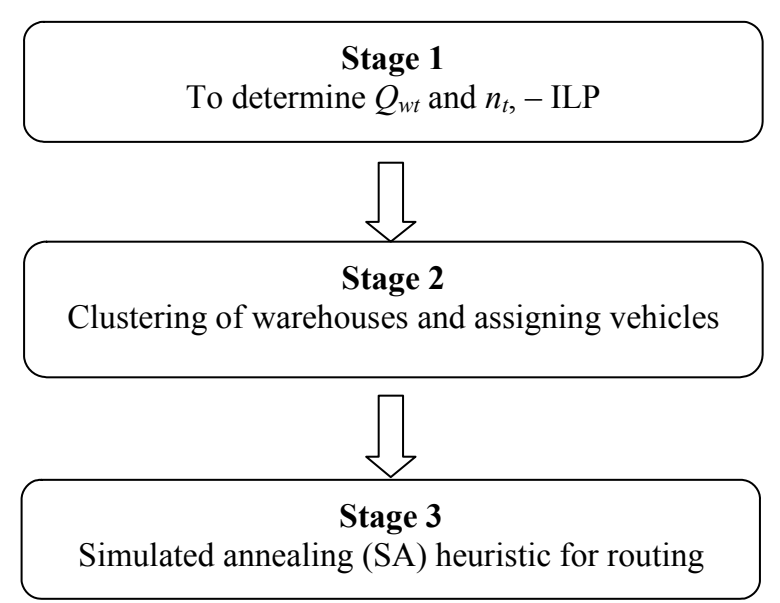

\subsubsection{Decision variables}

\begin{tabular}{lll}
\hline$Q_{w t}^{\prime}$ & Quantity transported from manufacturer to warehouse $w$ in time $t$ & $\forall e \in W, \forall t \in T$ \\
$n_{t}$ & Number of vehicles used in time period $t$ & $\forall t \in T$ \\
$I_{w}^{t}$ & Inventory of product in warehouse $w$ in time period $t$ & $\forall w \in W, \forall t \in T$ \\
$X_{M, w}^{t}$ & $\left\{\begin{array}{l}1, \text { if product is moved from manufacturer } M \text { to } w \text { in time } t \\
0, \text { otherwise }\end{array}\right.$ & $\forall w \in W, \forall t \in T$ \\
\hline
\end{tabular}

Minimise

$$
\sum_{t}^{T} \sum_{w}^{W} I C_{w} . I_{w}^{t}+\sum_{t}^{T} \sum_{w \in W} C_{M, w} . X_{M, w}^{t}+\sum_{t}^{T} F C . n_{t}
$$

Subject to

- Total vehicle capacity constraint

Quantity of products transported from manufacturer to warehouse w in a time period $\mathrm{t}$ should be less than or equal to the vehicle capacities.

$$
\sum_{w}^{W} Q_{w t}^{\prime} \leq V C A P . n_{t} \quad \forall t
$$

- Number of vehicles

The number of vehicles should be less than or equal to the total number of vehicles available.

$n_{t} \leq V$

$\forall t$

Integral constraints 
$Q_{w t}, n_{t}, I_{w}^{t} \geq 0$ and integers;

Binary constraints

$$
X_{M, w}^{t} \in\{0,1\}
$$

The ILP gives the customer-time period matrix, which comprises replenishment quantities for all warehouses at each time period and the number of vehicles utilised at each time period.

\subsubsection{Comparison between ILP for master problem and the ILP in hybrid heuristic}

Given that the inventory carrying costs at warehouses and fleet capacity in both the ILPs are same, allocation quantities depends solely on the routing costs. $C_{i, j}$ in ILP for the master problem is a dynamic variable based on $i, j \in\{W\}$, whereas in ILP used for stage 1 of hybrid heuristic, for each delivery node, an approximation is made by setting the arc-based transportation cost as an average of transportation costs for reaching that node to arrive at the allocation quantities. Therefore, allocations are approximations and are not optimal. For instance, hybrid heuristic

$$
\left(\sum_{t}^{T} \sum_{w}^{W} I C_{w} I_{w}^{t}\right)=\rho^{*} \text { Optimal }\left(\sum_{t}^{T} \sum_{w}^{W} I C_{w} I_{w}^{t}\right)
$$

where $\rho$ is a factor which represents the increase in total inventory cost from that of the optimal.

\subsection{Clustering using K-means algorithm}

Stage 2 comprises of a clustering algorithm to cluster warehouses taking into account vehicle capacities.

Using the solution obtained from stage 1, K-means algorithm is performed for each time period. Once cluster is done, the relocate operator is used to make the clusters feasible considering vehicle capacity and demand for each cluster. SA is then employed to determine the routes of the vehicles.

\subsubsection{Notations used in clustering}

\begin{tabular}{llc}
\hline$n e$ & Excess cluster & $(n e=1,2,3 \ldots N E)$ \\
$n s$ & Short cluster & $(n s=1,2,3 \ldots N S)$ \\
$k$ & Total number of clusters & $(k=1,2,3 \ldots K)$ \\
$T L_{k}$ & Total load in a cluster $k$ & \\
$E Q_{n e}$ & Excess quantity in an excess cluster $n e$ & \\
$S Q_{n s}$ & Short quantity in a short cluster $n s$ & \\
\hline
\end{tabular}

Excess cluster refers to a cluster which is capable of accommodating excess quantity. Short cluster refers to a cluster whose total demand is more than the vehicle capacity. 
- Relocate operator: A warehouse $w$ from short cluster $n s$ is relocated to an excess cluster ne which is capable of accommodating the warehouses' demand.

Algorithm 1 Clustering algorithm

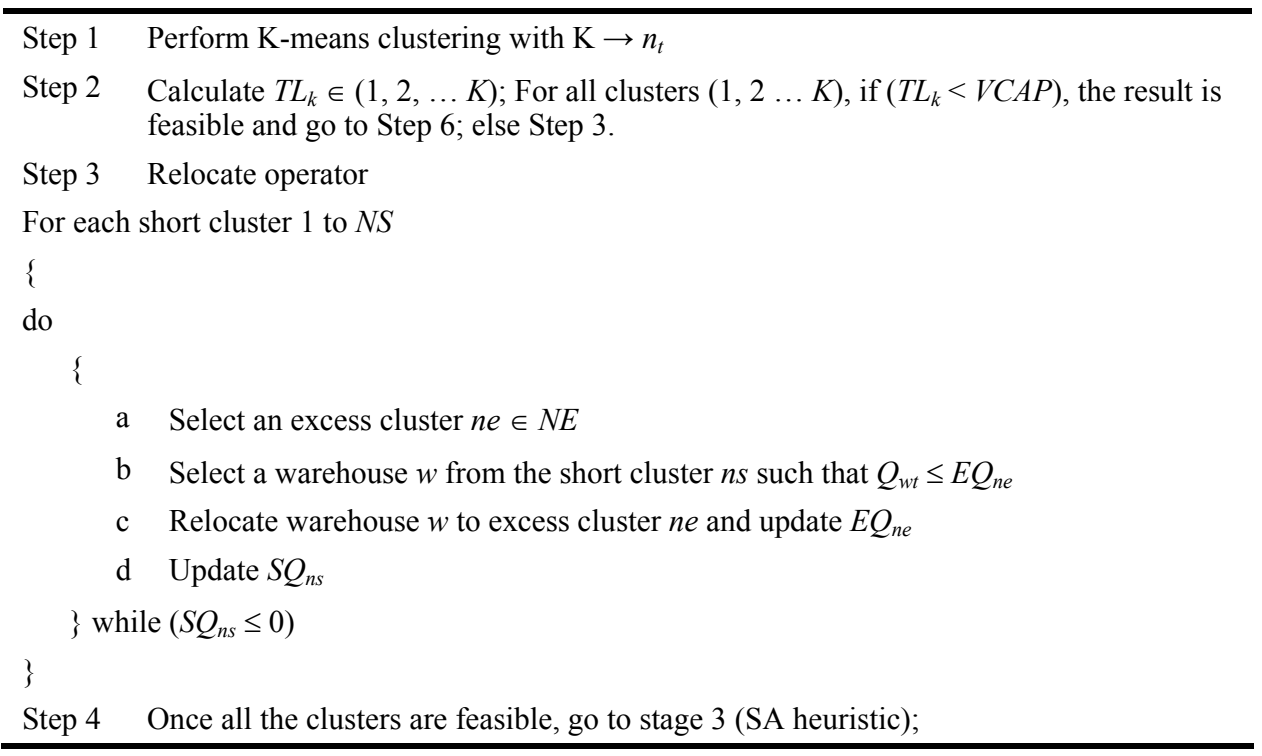

\subsection{Routing of vehicles $-S A$}

In stage $3, \mathrm{SA}$ is proposed to determine the routes of the vehicles.

\subsubsection{Notations used in $S A$}

\begin{tabular}{ll}
\hline$T_{j}$ & Temperature at iteration $j$ \\
$T_{i n i}$ & Initial temperature \\
$T_{f i n}$ & Final temperature \\
$N I$ & Number of iterations \\
$X_{i}$ & Solution vector in iteration $i$ \\
$f\left(X_{i}\right)$ & Objective value for solution vector $X_{i}$ \\
\hline
\end{tabular}

\subsubsection{Cooling scheme}

The following logarithmic cooling scheme (Lundy and Mees, 1986) has been used.

$$
T_{j+1}=\frac{T_{j}}{1+\lambda T_{j}},
$$

where

$$
\lambda=\frac{T_{i n i}-T_{f i n}}{N I \cdot T_{f i n} \cdot T_{i n i}}
$$


Number of iterations, $N I$ is kept as 10,000 (based on experimentation).

\subsubsection{Selection probability}

The probability of selection of an inferior solution $\left(X_{\text {new }}\right)$ is given by the following equation,

$$
P\left(T_{i}, X_{n e w}, X_{i}\right)=\exp ^{\left(-\Delta / T_{i}\right)}
$$

where

$$
\Delta=\frac{f\left(X_{\text {new }}\right)-f\left(X_{i}\right)}{f\left(X_{i}\right)} \times 100
$$

\subsubsection{Temperature settings}

Initial temperature is set at 47.4. The initial temperature is selected based on the inferiority of the perturbed solution (Parthasarathy and Rajendran, 1998). An inferior solution, inferior by $10 \%$ from the actual solution, is accepted with an associated probability of 0.9 .

$$
\begin{aligned}
& P=\exp (-\Delta / T) \\
& 0.9=\exp (-5 / T) \\
& T_{i n i}=47.4 ;
\end{aligned}
$$

Similarly, for final temperature, an inferior solution, inferior by $2 \%$ from the actual solution, is accepted with an associated probability of 0.05 .

$$
\begin{aligned}
& P=\exp (-\Delta / T) ; \\
& 0.05=\exp (-5 / T) ; \\
& T_{\text {fin }}=0.6 ;
\end{aligned}
$$

Termination condition: $N I=10,000$.

\subsubsection{Perturbation scheme}

We use the following perturbation schemes at different temperature zones (corresponding to different iteration zones), in order to have high diversification at high temperatures and high intensification at low temperatures

Table 2 Iteration zones vs. perturbation schemes

\begin{tabular}{lc}
\hline Iteration zones & Perturbation scheme \\
\hline 1 to $N I / 3$ & 3-opt perturbation scheme \\
$N I / 3$ to $2 . N I / 3$ & 2-opt perturbation scheme \\
$2 . N I / 3$ to $N I$ & Random swap \\
\hline
\end{tabular}

Notes: 3-opt perturbation scheme: in this scheme, three cells in a vector are exchanged with each other. 2-opt perturbation scheme: in this scheme, two cells in the vector are exchanged with each other. Random swap: two cells of the vector are selected randomly and are swapped. 
Algorithm 2 SA algorithm

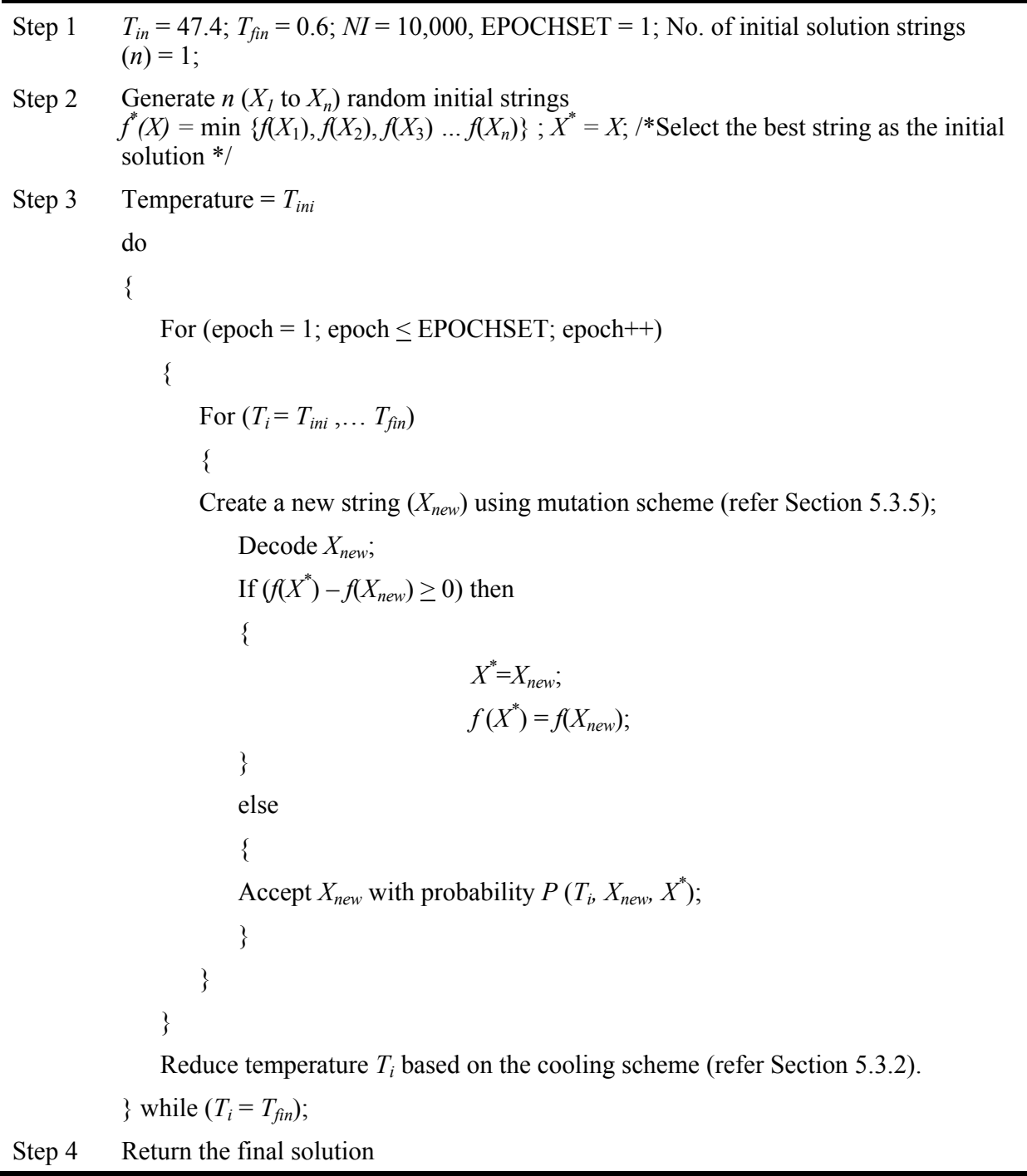

\section{Computational results and discussions}

The mathematical model and hybrid heuristic are evaluated by computational experiments conducted over datasets. Mathematical model has been solved using ILOG CPLEX 9.0, and hybrid heuristic using ILOG Concert in Microsoft Visual C++ 6.0.

\subsection{Experimental design}

To test the proposed solution approaches, 60 instances have been generated and these are comparable to the instances available in literature. Warehouses are located randomly in a 
grid of size $50 \times 50$. The coordinates for the warehouses are generated using a uniform distribution while the manufacturer is fixed at the centre of the grid. Datasets are generated for the following conditions based on the pattern of Abdelmaguid et al. (2009).

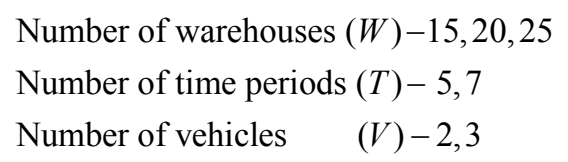

We consider three levels of $W(15,20$, and 25), two levels of $T(5,7)$ and two levels of $V$ $(2,3)$ and obtain 12 datasets with different combination of levels of $W, T$ and $V(3 * 2 * 2=12)$.

We define a ratio

$$
V C R=\frac{\text { Total vehicle capacity }- \text { Average demand per time period }}{\text { Average demand per time period }}
$$

$V C R$ value is set as 1.5. To account for randomness, five instances have been generated for each dataset. Demands for warehouses have been generated from a uniform distribution over the range $\{1,30\}$ (Aghezzaf et al., 2006). Transportation costs between different warehouses have been calculated using Euclidean distances. Inventory holding costs at warehouses is taken as 1 per unit per unit time period. A fixed cost of operating each vehicle is set as ten (Abdelmaguid and Dessouky, 2006; Abdelmaguid et al., 2009). The naming convention used for the datasets starts with number of warehouses followed by number of time periods, number of vehicles and replication number each separated by hyphen. For example, first replication of a dataset with $W=15$, $T=5, V=2$ is represented as 15-5-2-1. Table 3 shows the network characteristics of test datasets.

Table 3 Network characteristics of datasets

\begin{tabular}{lcccccccccccc}
\hline Dataset & 1 & 2 & 3 & 4 & 5 & 6 & 7 & 8 & 9 & 10 & 11 & 12 \\
\hline $\mathrm{W}$ & 15 & 15 & 15 & 15 & 20 & 20 & 20 & 20 & 25 & 25 & 25 & 25 \\
$\mathrm{~T}$ & 5 & 5 & 7 & 7 & 5 & 5 & 7 & 7 & 5 & 5 & 7 & 7 \\
$\mathrm{~V}$ & 2 & 3 & 2 & 3 & 2 & 3 & 2 & 3 & 2 & 3 & 2 & 3 \\
$\mathrm{VCAP}$ & 300 & 225 & 300 & 225 & 400 & 300 & 400 & 300 & 500 & 400 & 500 & 400 \\
\hline
\end{tabular}

\subsection{Computational study - mathematical model}

The proposed ILP model is tested on a set of 60 problem instances, which were solved using ILOG CPLEX 9.0 on a PC with INTEL(R) Core (TM) 2 Duo Processor @ $3 \mathrm{GHz}$, 2.0 GB RAM. The problem instances were run for a stipulated time of 1 hour. ILOG CPLEX 9.0 was able to provide optimal solutions for most of the datasets. Owing to the inherent NP hard nature of the problem, it is computationally difficult to obtain optimal solution for rest of the datasets. Within the pre-set time limit of 1 hour, ILOG CPLEX 9.0 yielded feasible solutions which have been used as upper bound solutions for comparison. Instances which failed to provide a feasible solution within an hour is run with a time limit of about three hours. The results are summarised in Table 4. 
Table 4 Computational results

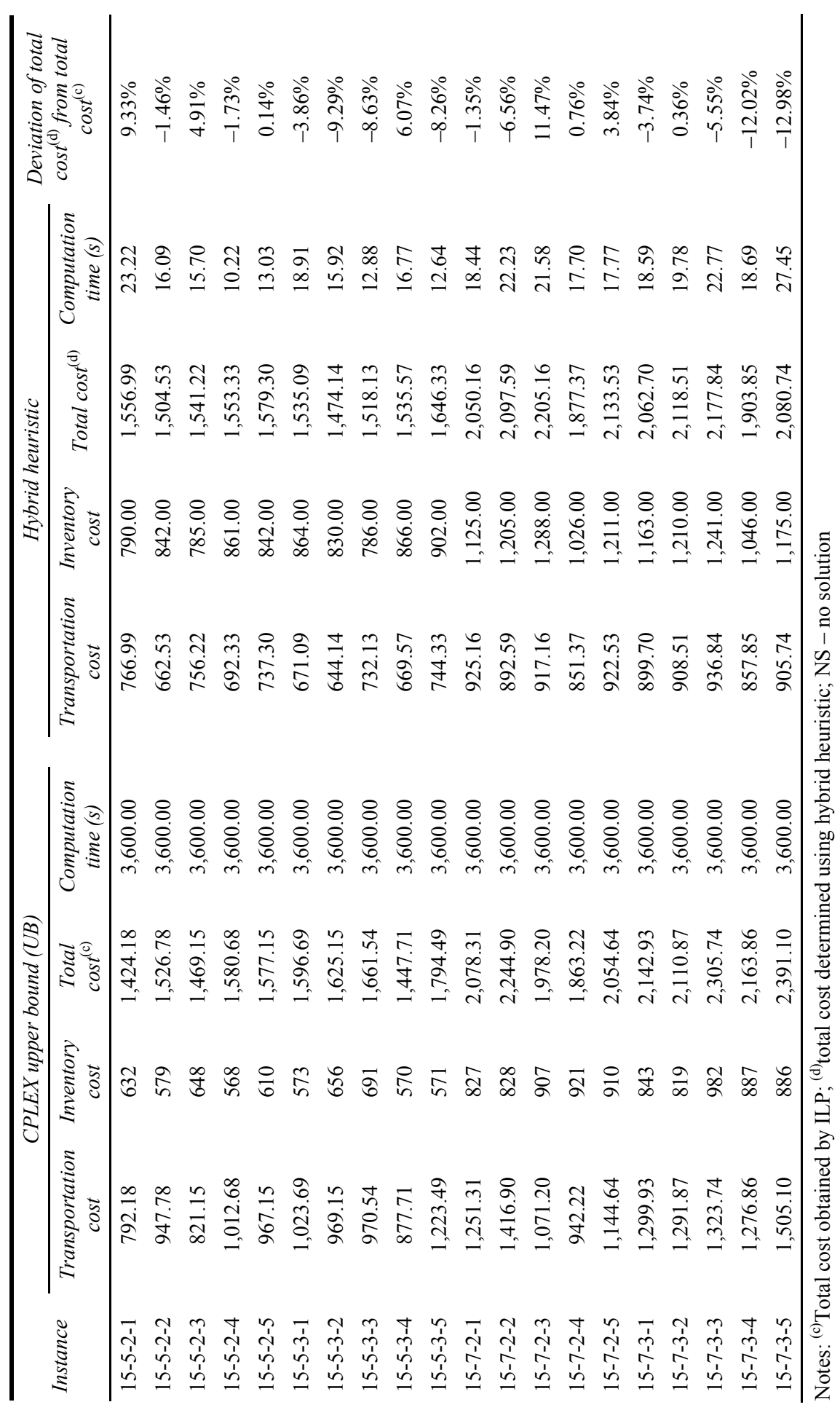


Table 4 Computational results (continued)

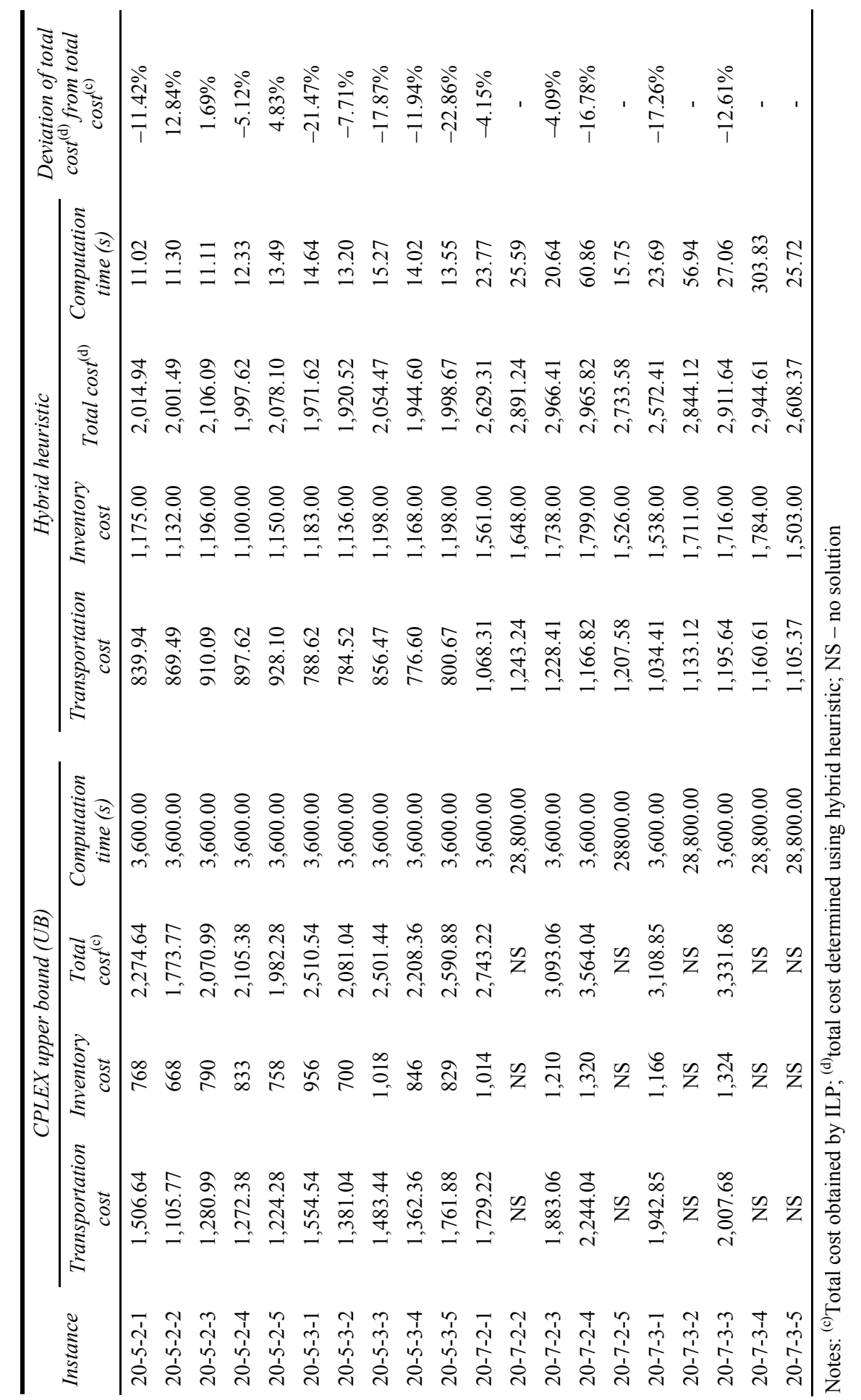


Table 4 Computational results (continued)

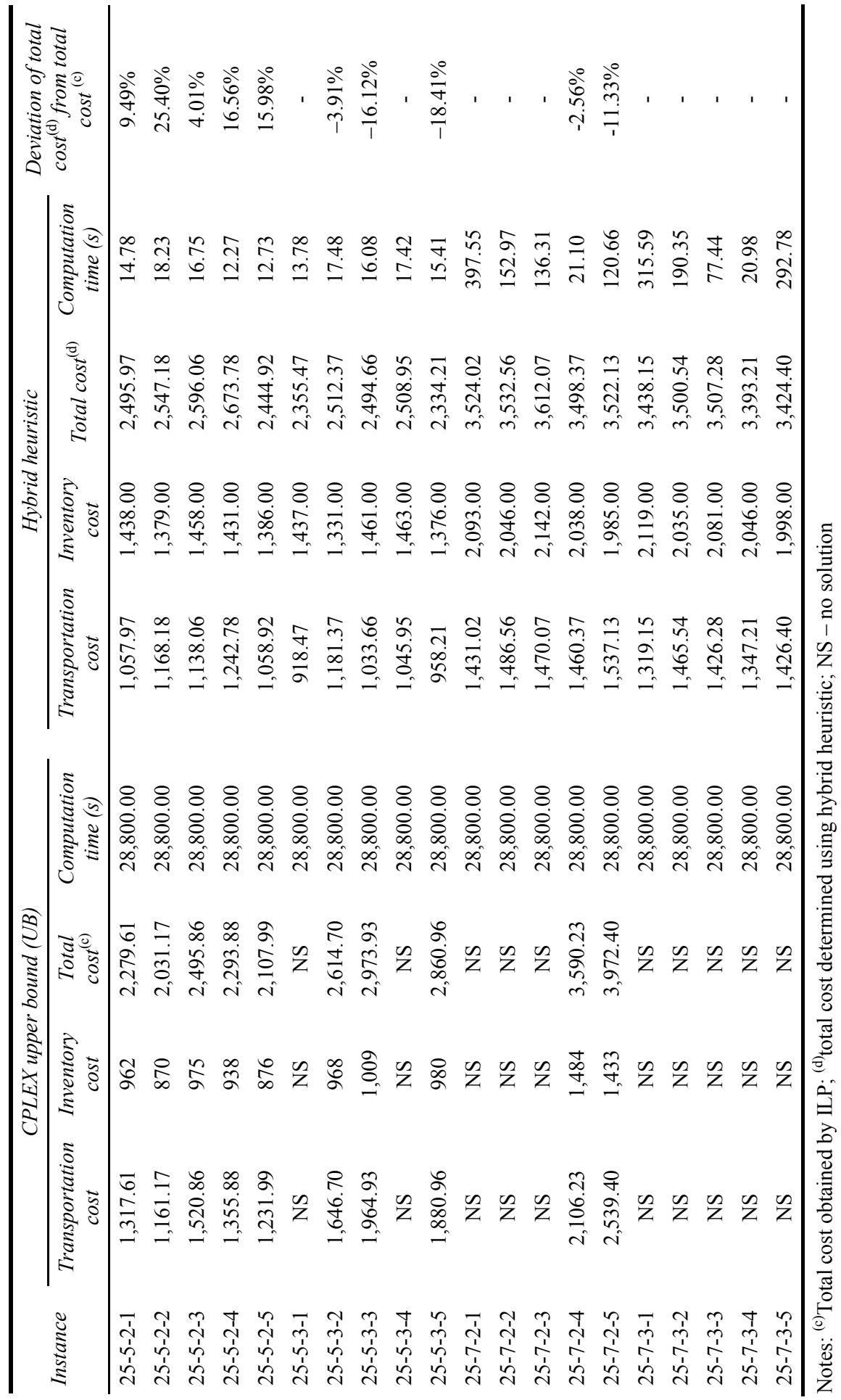




\subsection{Computational study-hybrid heuristic}

The proposed heuristic is evaluated against 60 instances which were run using ILOG Concert in Microsoft Visual C++ 6.0 on the PC with INTEL(R) Core (TM) 2 Duo Processor@3 GHz, 2.0 GB RAM. Results are shown in Table 4 along with transportation and inventory cost components. The computation times for all the instances are also shown in Table 4.

Solutions obtained from heuristic are compared with upper bound solutions obtained from CPLEX. In most of the instances, results obtained from heuristic outperform upper bound solutions. On comparing the solutions obtained with upper bound solutions, heuristic yields solutions better than the upper bound from ILOG CPLEX 9.0 with an average gap of about $5 \%$ (Figure 2).

Figure 2 Performance of hybrid heuristic (see online version for colours)

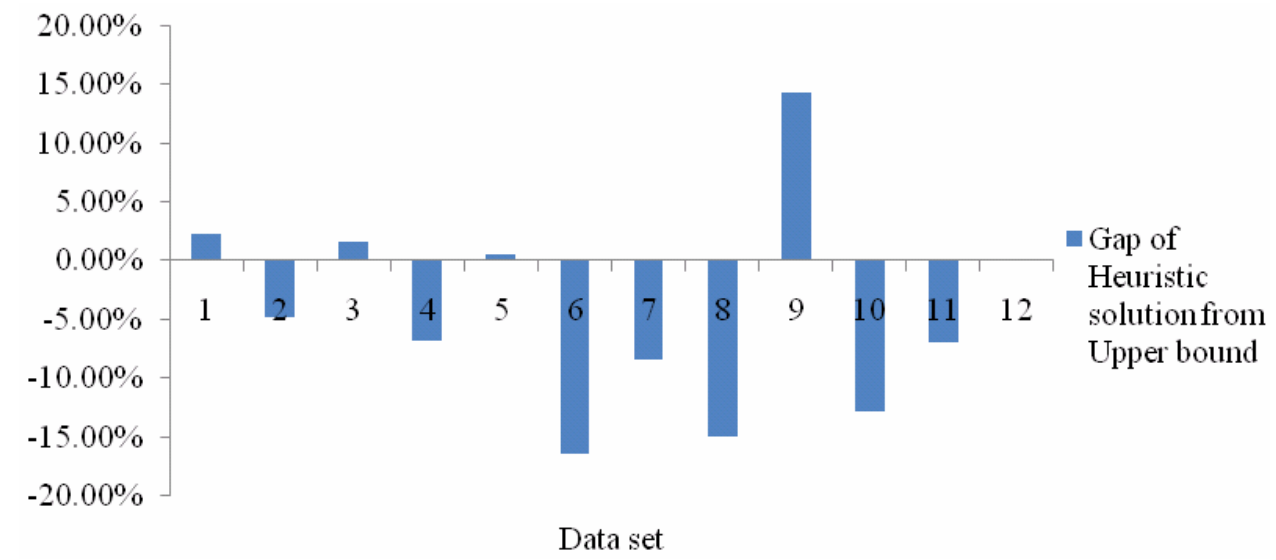

In some instances, ILOG CPLEX could not provide feasible solutions with a preset time limit of 1 hour. But, heuristic is found to be capable of providing feasible solutions in negligible amount of time to such instances. Computational times of proposed heuristic are far less compared to the computational time for arriving at the upper bound solutions from CPLEX. Hybrid heuristic is relatively efficient in terms of computation time and quality of solutions.

\section{Conclusions}

We have addressed an IRP with explicit consideration of safety stocks at warehouses and modelled it as an ILP. We propose a hybrid heuristic and test it over datasets of various sizes. Against the bench-mark of upper bound solutions obtained from CPLEX, the heuristic is found to fetch good solutions in quick computing time.

The proposed method can be used by real-world VMI systems in the manufacturing sector. It can be extended to solve problems with multiple objectives. It has scope for application to different network structures with multiple sources (multi-depot IRP) and/or with a central depot(s) and for extensions that consider travel time, loading/unloading time and warehouse operating time. 


\section{References}

Abdelmaguid, T.F. and Dessouky, M.M. (2006) 'A genetic algorithm approach to the integrated inventory-distribution problem', International Journal of Production Research, Vol. 44, No. 21, pp.4445-4464.

Abdelmaguid, T.F., Dessouky, M.M. and Ordonez, F. (2009) 'Heuristic approaches for the inventory-routing problem with backlogging', Computers \& Industrial Engineering, Vol. 56, No. 4, pp.1519-1534.

Aghezzaf, E.H., Raa, B. and van Landeghem, H. (2006) 'Modeling inventory routing problems in supply chains of high consumption products', European Journal of Operational Research, Vol. 169, No. 3, pp.1048-1063.

Al-Khayyal, F. and Hwang, S.J. (2007) 'Inventory constrained maritime routing and scheduling for multi-commodity liquid bulk, part I: applications and model', European Journal of Operational Research, Vol. 176, No. 1, pp.106-130.

Andersson, H., Hoff, A., Christiansen, M., Hasle, G. and Løkketangen, A. (2010) 'Industrial aspects and literature survey: combined inventory management and routing', Computers \& Operations Research, Vol. 37, No. 9, pp.1515-1536.

Archetti, C., Bertazzi, L., Laporte, G. and Speranza, M.G. (2007) 'A branch-and-cut algorithm for a vendor-managed inventory-routing problem', Transportation Science, Vol. 41, No. 3 , pp.382-391.

Bard, J., Huang, L., Jaillet, P. and Dror, M. (1998) 'A decomposition approach to the inventory routing problem with satellite facilities', Transportation Science, Vol. 32, No. 2, pp.189-203.

Bertazzi, L., Paletta, G. and Speranza, M.G. (2002) 'Deterministic order-up-to level policies in an inventory routing problem', Transportation Science, Vol. 36, No. 1, pp.119-132.

Blumenfeld, D.E., Burns, L.D., Diltz, J.D. and Daganzo, C.F. (1985) 'Analyzing trade-offs between transportation, inventory and production costs on freight networks', Transportation Research Part B, Vol. 19, No. 5, pp.361-380.

Bramel, J. and Simchi-Levi, D. (1995) 'A location based heuristic for general routing problems', Operations Research, Vol. 43, No. 4, pp.649-660.

Burns, L.D., Hall, R.W., Blumenfeld, D.E. and Daganzo, C.F. (1985) 'Distribution strategies that minimize transportation and inventory costs', Operations Research, Vol. 33, No. 3, pp.469-490.

Campbell, A.M. and Savelsbergh, M.W.P. (2004) 'A decomposition approach for the inventory-routing problem', Transportation Science, Vol. 38, No. 4, pp.488-502.

Chandra, P. (1993) 'A dynamic distribution model with warehouse and customer replenishment requirements', Journal of the Operational Research Society, Vol. 44, No. 7, pp.681-692.

Disney, S.M. and Towill, D.R. (2002) 'A procedure for the optimization of the dynamic response of a vendor managed inventory system', Computers \& Industrial Engineering, Vol. 43, Nos. 1/2, pp.27-58.

Federgruen, A. and Zipkin, P.H. (1984) 'A combined vehicle routing and inventory allocation problem’, Operations Research, Vol. 32, No. 5, pp.1019-1037.

Gallego, G. and Simchi-Levi, D. (1990) 'On the effectiveness of direct shipping strategy for the one-warehouse multi-retailer R-systems', Management Science, Vol. 36, No. 2, pp.240-243.

Kim, J.U. and Kim, Y.D. (2000) 'A Lagrangian relaxation approach to multi-period inventory/distribution planning', Journal of the Operational Research Society, Vol. 51, No. 3, pp.364-370.

Larson, R.C. (1988) 'Transporting sludge to the 106-mile site - an inventory routing model for fleet sizing and logistics system-design', Transportation Science, Vol. 22, No. 3, pp.186-198.

Lundy, M. and Mees, A. (1986) 'Convergence of an annealing algorithm', Mathematical Programming, Vol. 34, No. 1, pp.111-124. 
Oppen, J., Løkketangen, A. and Desrosiers, J. (2010) 'Solving a rich vehicle routing and inventory problem using column generation', Computers \& Operations Research, Vol. 37, No. 7, pp.1308-1317.

Parthasarathy, S. and Rajendran, C. (1998) 'Scheduling to minimize mean tardiness and weighted mean tardiness in flowshop and flowline-based manufacturing cell', Computers \& Industrial Engineering, Vol. 34, No. 2, pp.531-546.

Raa, B. and Aghezzaf, E.H. (2008) 'Designing distribution patterns for long-term inventory routing with constant demand rates', International Journal of Production Economics, Vol. 112, No. 1, pp.255-263.

Raa, B. and Aghezzaf, E.H. (2009) 'A practical solution approach for the cyclic inventory routing problem', European Journal of Operational Research, Vol. 192, No. 2, pp.429-441.

Roundy, R. (1985) '98\%-effective integer-ratio lot-sizing for one-warehouse multi-retailer systems', Management Science, Vol. 31, No. 11, pp.1416-1430.

Rusdiansyah, A. and Tsao, D. (2005) 'An integrated model for the periodic delivery problems for vending-machine supply chains', Journal of Food Engineering, Vol. 70, No. 3, pp.421-434.

Stacey, J., Natarajarathinam, M. and Sox, C. (2007) 'The storage constrained, inbound inventory routing problem', International Journal of Physical Distribution \& Logistics Management, Vol. 37, No. 6, pp.484-500.

Taarit, N.B., Mansouri, F.Z. and Alouane, A.B.H. (2009) A Lagrangian Heuristic Approach for the Inventory Routing Problem, IEEE.

Webb, I.R. and Larson, R.C. (1995) 'Period and phase of customer replenishment - a new approach to the strategic inventory/routing problem', European Journal of Operational Research, Vol. 85, No. 1, pp.132-148.

Yugang, Y., Haoxun, C. and Feng, C. (2008) 'A new model and hybrid approach for large scale inventory routing problems', European Journal of Operational Research, Vol. 189, No. 3, pp.1022-1040.

\section{Notes}

$1 \quad C_{i j}=\operatorname{cost} / \mathrm{km} \times d_{i j}$ 